\title{
Crystal Structures and Magnetic Properties of Polyethylene Glycol (PEG-4000) Encapsulated $\mathrm{Co}_{0.5} \mathrm{Ni}_{0.5} \mathrm{Fe}_{2} \mathrm{O}_{4}$ Magnetic Nanoparticles
}

\author{
Edi Suharyadi ${ }^{1 *}$, Lintang Griyanika ${ }^{1}$, Joko Utomo ${ }^{1}$, Ayu Kurnia Agustina1, \\ Takeshi Kato ${ }^{2}$ and Satoshi Iwata ${ }^{3}$ \\ ${ }^{1}$ Department of Physics, Universitas Gadjah Mada, Yogyakarta, Indonesia \\ ${ }^{2}$ Department of Electronics, Nagoya University, Japan \\ ${ }^{3}$ Institute of Materials and Systems for Sustainability, Nagoya University, Japan \\ *Email: esuharyadi@ugm.ac.id
}

\begin{abstract}
Nanocrystalline mixed spinel ferrite of $\mathrm{Co}_{0.5} \mathrm{Ni}_{0.5} \mathrm{Fe}_{2} \mathrm{O}_{4}$ magnetic nanoparticles (MNPs) has been successfully synthesized by coprecipitation method and encapsulated by PEG-4000 with various concentrations. X-Ray Diffraction (XRD) patterns showed that nanoparticles contained $\mathrm{Co}_{0.5} \mathrm{Ni}_{0.5} \mathrm{Fe}_{2} \mathrm{O}_{4}$ spinel ferrite with crystallite size of $14.9 \mathrm{~nm}$. After PEG-4000 encapsulation particles size decreased became $7.7 \mathrm{~nm}$. Interaction $\mathrm{Co}_{0.5} \mathrm{Ni}_{0.5} \mathrm{Fe}_{2} \mathrm{O}_{4}$ nanoparticles with long chain PEG-4000 caused the crystal growth trap. Lattice parameter and $\mathrm{X}$-Ray density have no significant difference after encapsulated PEG-4000. The coercivity $\left(H_{c}\right)$ of $\mathrm{Co}_{0.5} \mathrm{Ni}_{0.5} \mathrm{Fe}_{2} \mathrm{O}_{4}$ was $214 \mathrm{Oe}$. The $H_{c}$ decreased after PEG-4000 encapsulation became $127 \mathrm{Oe}$, which is due to the decrease of crystallite size. The maximum magnetization (Mmax) of $\mathrm{Co}_{0.5} \mathrm{Ni}_{0.5} \mathrm{Fe}_{2} \mathrm{O}_{4}$ was $12.0 \mathrm{emu} / \mathrm{g}$, and decreased after PEG-4000 encapsulation to 11.7 emu/g, because PEG-4000 is paramagnetic. After the concentration of PEG-4000 increased, then the amount of paramagnetic material increase which lead maximum magnetization decrease.
\end{abstract}

Keywords: Spinel Ferrite, Magnetic Nanoparticles, Coprecipitation, CoNi Ferrites.

\section{INTRODUCTION}

Ferrite nanoparticles (FNPs) belong to a broad group of magnetic nanoparticles (MNPs) due to their unique properties, such as superparamagnetism, greater surface area, and easy separation methodology ${ }^{[1]}$. The important group of ferrite is spinel ferrite with general formula $\mathrm{MFe}_{2} \mathrm{O}_{4}$ (where $\mathrm{M}=\mathrm{Mn}, \mathrm{Fe}, \mathrm{Co}, \mathrm{Ni}, \mathrm{Cu}$ and $\mathrm{Zn}$ ), and most of them show superparamagnetic (SPM) properties at the size below or about $20 \mathrm{~nm}$ in diameter ${ }^{[2]}$. Spinel ferrite NPs are received a considerable amount of attention due to their wide applications in various fields, which ranges from biomedical to industrial ${ }^{[2]}$.

Cobalt ferrite $\left(\mathrm{CoFe}_{2} \mathrm{O}_{4}\right)$ and nickel ferrite $\left(\mathrm{NiFe}_{2} \mathrm{O}_{4}\right)$ are the examples of spinel ferrite NPs. Both of them have invers spinel structure ${ }^{[3,4]}$. The properties of $\mathrm{CoFe}_{2} \mathrm{O}_{4}$ are hard magnetic, high magnetic saturation, and high coercivity ${ }^{[5]}$. On the other hand, the properties of $\mathrm{NiFe}_{2} \mathrm{O}_{4}$ are soft magnetic, low magnetic saturation, and low coercivity ${ }^{[6]}$. The mixture of $\mathrm{CoFe}_{2} \mathrm{O}_{4}$ and $\mathrm{NiFe}_{2} \mathrm{O}_{4}$ with the same concentration would be $\mathrm{Co}_{0.5} \mathrm{Ni}_{0.5} \mathrm{Fe}_{2} \mathrm{O}_{4}$, which have the new properties such as mix spinel, hard magnetic, the magnetic saturation and coercivity between $\mathrm{NiFe}_{2} \mathrm{O}_{4}$ and $\mathrm{CoFe}_{2} \mathrm{O}_{4}{ }^{[7]}$. Due to the properties, $\mathrm{Co}_{0.5} \mathrm{Ni}_{0.5} \mathrm{Fe}_{2} \mathrm{O}_{4}$ have a possibility to be applied in biomedical application such as drug delivery.

Various synthesis routes have been studied for the preparation of $\mathrm{CoNiFe}_{2} \mathrm{O}_{4}$ nanoparticles, such as sol-ge $]^{[8]}$, hydrothermal ${ }^{[9]}$, co-precipitation ${ }^{[10]}$, aerosol-route ${ }^{[11]}$, glycol thermal-process ${ }^{[12]}$, etc. The most commonly used is co-precipitation method 
because it have advantages over physical methods, such as low cost, simple and rapid preparation, high purity of product, and not requiring heat threatment. But, ferrite NPs prepared with co-precipitation method are easily agglomerated. So, a way to overcome this difficulty is the encapsulation of magnetic NPs with biopolimer, such as polyethylene glycol (PEG). Magnetic nanoparticles in their simplest form are composed of an inorganic magnetic compound (usually a ferrite such as $\mathrm{Fe}_{3} \mathrm{O}_{4}$ and $\mathrm{MFe}_{2} \mathrm{O}_{4}(\mathrm{M}=\mathrm{Ni}, \mathrm{Co}, \mathrm{Mn})$ ) core. MNPs should be pre-coated with some substance (shell) that can assure their stability, biodegradability, and non-toxicity in physiological medium and maintain the high magnetic saturation required and be a functional surface ${ }^{[13]}$.

Kavas et al. ${ }^{[14]}$, studied the magnetic characterization of ferrite nanoparticles encapsulated PEG, but this precursor has short chain polymer and high cost. So, we use PEG-4000 because it has long chain polymer and to reduce the cost incurred. Based to their paper, Kavas et al used hydrothermal route to encapsulating ferrite NPs, so this method requiring high temperature. Therefore, in this research, we have used co-precipitation method for making $\mathrm{Co}_{0.5} \mathrm{Ni}_{0.5} \mathrm{Fe}_{2} \mathrm{O}_{4}$ nanoparticles. However, through the literature review, the magnetic characterization of $\mathrm{Co}_{0.5} \mathrm{Ni}_{0.5} \mathrm{Fe}_{2} \mathrm{O}_{4}$ nanoparticles encapsulated PEG in particular has never been investigated. So, the aim of our investigation was study how variation of concentration of PEG-4000 as encapsulate substrate. In order to study the influences of encapsulate substrate on crystal structures, morphological, and magnetic properties of $\mathrm{Co}_{0.5} \mathrm{Ni}_{0.5} \mathrm{Fe}_{2} \mathrm{O}_{4}$ nanoparticles. Further the information mechanism is discussed in detail.

\section{EXPERIMENTAL DETAILS}

The precursor such as $\mathrm{FeCl}_{3} \cdot 6 \mathrm{H}_{2} \mathrm{O}$ (Merck, Germany), $\mathrm{CoCl}_{2} \cdot 6 \mathrm{H}_{2} \mathrm{O}$ (Merck, Germany), $\mathrm{NiCl}_{2} \cdot 6 \mathrm{H}_{2} \mathrm{O}$ (Merck, Germany) and $\mathrm{NaOH}$ (Merck, Germany) were weighed carefully in accordance with the required stoichiometric proportion of salt. $\mathrm{Mix} \mathrm{CoCl}_{2} \cdot 6 \mathrm{H}_{2} \mathrm{O}$ salt and $\mathrm{NiCl}_{2} \cdot 6 \mathrm{H}_{2} \mathrm{O}$ salt and dissolved it in $25 \mathrm{ml}$ aquadest. Dissolved each $\mathrm{FeCl}_{3} \cdot 6 \mathrm{H}_{2} \mathrm{O}$ salt and $\mathrm{NaOH}$ salt in $25 \mathrm{ml}$ of aquadest. Then, mix the metal solution and add $3.37 \mathrm{ml} \mathrm{HCl} 37 \%$ (Merck, Germany) into it. The precipitation was carried out by dropping the alloys solution into $12 \mathrm{M} \mathrm{NaOH}$ solution called sample respectively, at temperature $90^{\circ} \mathrm{C}$ respectively, for 1 hour and stirred at $1000 \mathrm{rpm}$. The precipitate then washed 7 times for 30 minutes and dried at $90^{\circ} \mathrm{C}$ for 4 hours.

The various PEG solution was dropped into $25 \mathrm{ml} \mathrm{NaOH}$ when co-precipitation process. The concentration of PEG-4000 is used as in Table 1.

Table 1. Variation of the concentration of PEG-4000

\begin{tabular}{ccc}
\hline Sample & \multicolumn{2}{c}{ Comparison of PEG-4000 in molarity } \\
\cline { 2 - 3 } & $\begin{array}{c}\text { Proportion NaOH : PEG 4000 } \\
\text { at } 2 \text { ml aquades }\end{array}$ & $\begin{array}{c}\text { PEG Molarity mixed } \\
\text { in NaOH (M) }\end{array}$ \\
\hline P1 & $12.0 \mathrm{gr}: 0.5 \mathrm{gr}$ & 0.005 molar \\
P2 & $12.0 \mathrm{gr}: 1 \mathrm{gr}$ & 0.011 molar \\
P3 & $12.0 \mathrm{gr}: 1.5 \mathrm{gr}$ & 0.016 molar \\
P4 & $12.0 \mathrm{gr}: 2 \mathrm{gr}$ & 0.021 molar \\
P5 & $12.0 \mathrm{gr}: 2.5 \mathrm{gr}$ & 0.026 molar \\
P6 & $12.0 \mathrm{gr}: 3 \mathrm{gr}$ & 0.032 molar \\
\hline
\end{tabular}

The crystal structures were analyzed by X-ray diffractometer (XRD) Shimadzu XD with $\mathrm{CuK} \alpha 1$ radiation $(\lambda=1.5406 \AA)$. The magnetic properties were analyzed by Vibrating Sample Magnetometer (VSM) Riken Denshi Co. Ltd. with applying external magnetic field $15 \mathrm{KOe}$ at room temperature. 


\section{RESULT AND DISCUSSION}

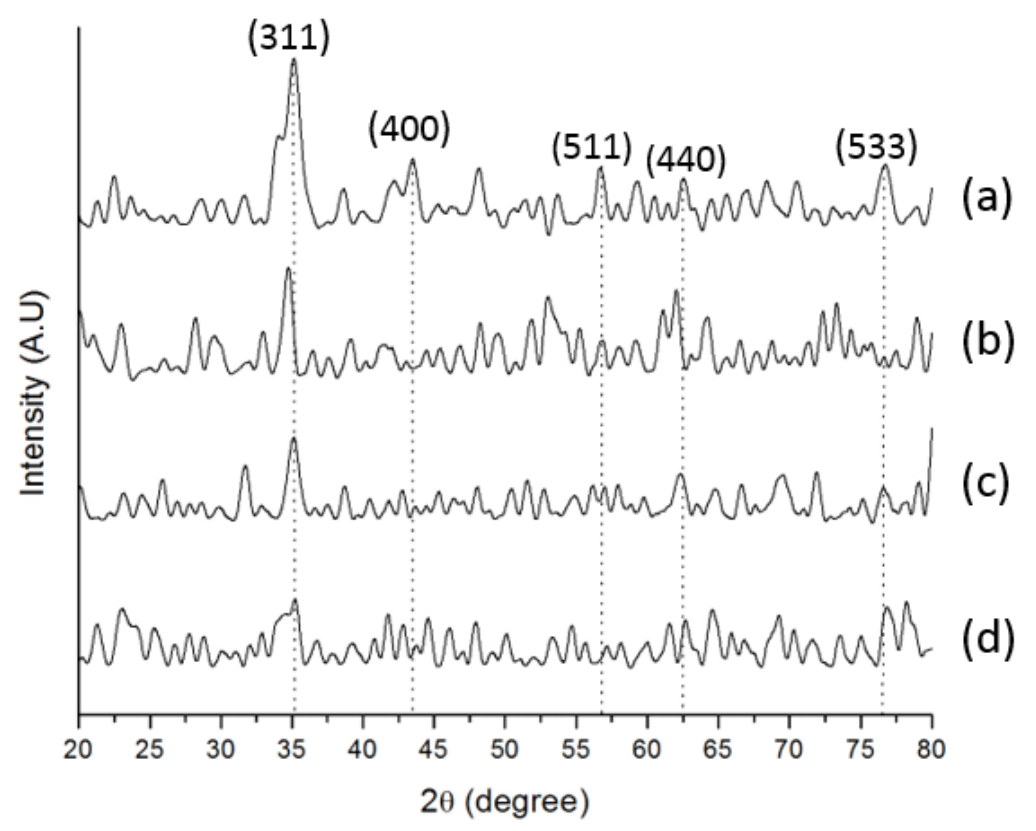

Figure 1. XRD patterns of $\mathrm{Co}_{0.5} \mathrm{Ni}_{0.5} \mathrm{Fe}_{2} \mathrm{O}_{4}$ nanoparticles, (a) before, (b) after encapsulated 1 g PEG-4000, (c) 1.5 g PEG-4000 and (d) 3 g PEG-4000

Structural studies were done with XRD measurement and then compared to standard data (JCPDS no 45-0131) in $2 \theta$ range of $20^{\circ}-80^{\circ}$ to $\mathrm{Co}_{0.5} \mathrm{Ni}_{0.5} \mathrm{Fe}_{2} \mathrm{O}_{4}$ nanoparticles, as shown in Fig. 1. XRD patterns showed that nanoparticles contained $\mathrm{Co}_{0.5} \mathrm{Ni}_{0.5} \mathrm{Fe}_{2} \mathrm{O}_{4}$ spinel ferrite because all sample show the diffraction peak from (311). Table 2 show the crystallite size, $\mathrm{X}$-Ray density, and lattice parameter. Crystallite size of $\mathrm{Co}_{0.5} \mathrm{Ni}_{0.5} \mathrm{Fe}_{2} \mathrm{O}_{4}$ before encapsulation is $14.9 \mathrm{~nm}$. After PEG-4000 encapsulation, crystallite size decreased became $9.3 \mathrm{~nm}, 8.6 \mathrm{~nm}$ and $7.7 \mathrm{~nm}$ for PEG-4000 adding of 1; 1.5; 3 grams, respectively. Because interaction $\mathrm{Co}_{0.5} \mathrm{Ni}_{0.5} \mathrm{Fe}_{2} \mathrm{O}_{4}$ nanoparticles with long chain PEG-4000 cause the crystal growth will trap. Lattice parameter and X-Ray density have no significant difference after encapsulated PEG-4000.

Table 2. Analysis XRD of $\mathrm{Co}_{0.5} \mathrm{Ni}_{0.5} \mathrm{Fe}_{2} \mathrm{O}_{4}$ before and after encapsulated with PEG-4000

\begin{tabular}{|c|c|c|c|}
\hline MATERIAL & $\begin{array}{l}\text { Crystallite } \\
\text { size (nm) }\end{array}$ & $\begin{array}{l}\text { X-Ray } \\
\text { density } \\
\left(\mathrm{g} / \mathrm{cm}^{3}\right)\end{array}$ & $\begin{array}{c}\text { Lattice } \\
\text { parameter }(\mathbf{n m})\end{array}$ \\
\hline $\mathrm{Co}_{0.5} \mathrm{Ni}_{0.5} \mathrm{Fe}_{2} \mathrm{O}_{4}$ & 14.9 & 5.2 & 8.47 \\
\hline $\mathrm{Co}_{0.5} \mathrm{Ni}_{0.5} \mathrm{Fe}_{2} \mathrm{O}_{4}+1$ g PEG-4000 & 9.3 & 5.2 & 8.56 \\
\hline $\mathrm{Co}_{0.5} \mathrm{Ni}_{0.5} \mathrm{Fe}_{2} \mathrm{O}_{4}+1.5 \mathrm{~g}$ PEG-4000 & 8.6 & 5.2 & 8.47 \\
\hline $\mathrm{Co}_{0.5} \mathrm{Ni}_{0.5} \mathrm{Fe}_{2} \mathrm{O}_{4}+3$ g PEG-4000 & 7.7 & 5.1 & 8.42 \\
\hline
\end{tabular}



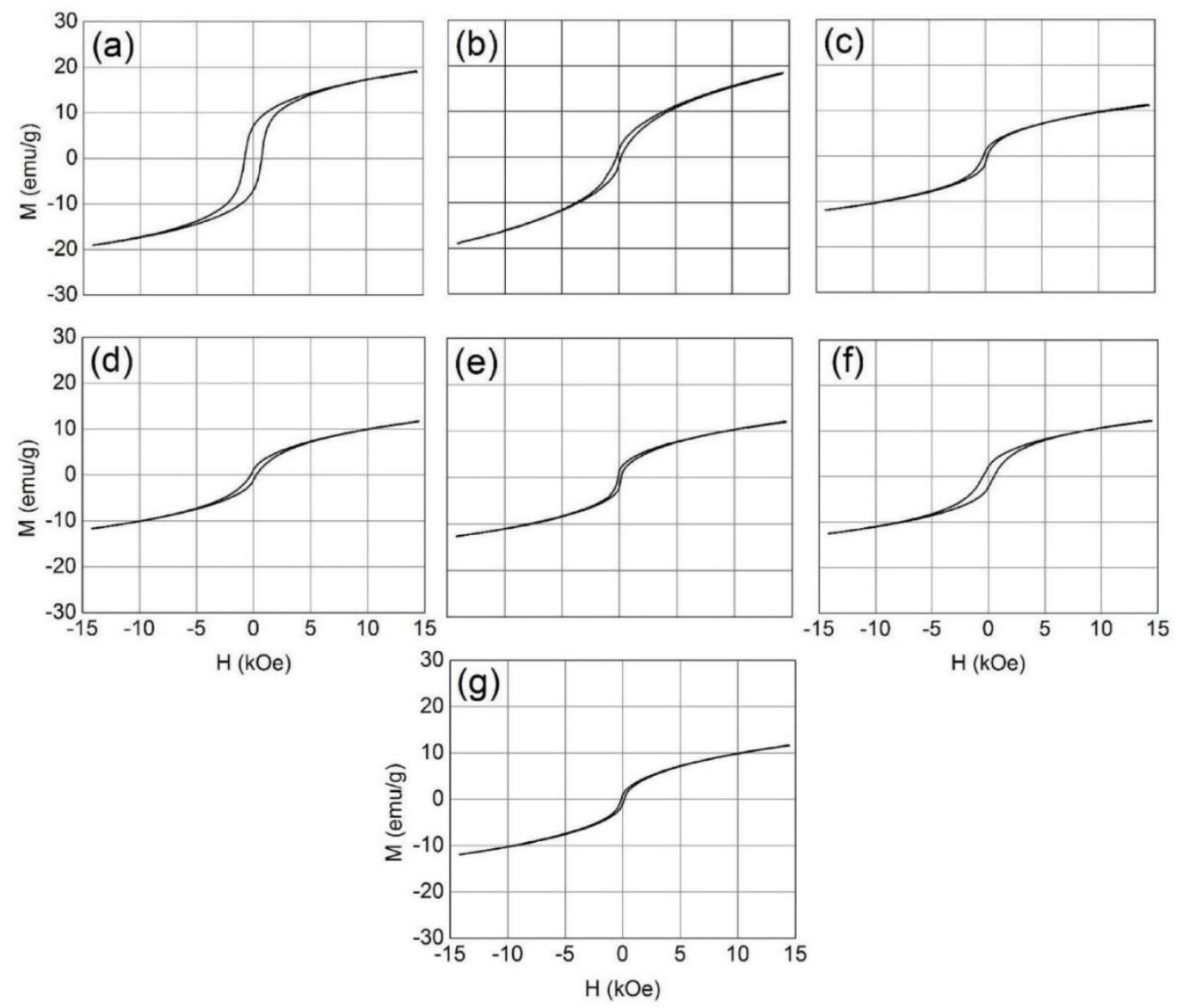

Figure 2. Hysteresis curves of $\mathrm{Co}_{0.5} \mathrm{Ni}_{0.5} \mathrm{Fe}_{2} \mathrm{O}_{4}$ encapsulated PEG-4000 (a) before, and after encapsulated (b) $0.5 \mathrm{~g}$, (c) $1 \mathrm{~g}$, (d) $1.5 \mathrm{~g}$, (e) $2 \mathrm{~g}$, (f) $2.5 \mathrm{~g}$, dan (g) $3 \mathrm{~g}$.

Table 3. Magnetic Properties of $\mathrm{Co}_{0.5} \mathrm{Ni}_{0.5} \mathrm{Fe}_{2} \mathrm{O}_{4}$ Before and After Encapsulated PEG-4000

\begin{tabular}{cccc}
\hline $\begin{array}{c}\text { PEG-4000 } \\
\text { Concentration } \\
\text { (gram) }\end{array}$ & $\begin{array}{c}\mathbf{M}_{\text {max }}(\mathbf{1 5} \mathbf{~ k O e}) \\
(\mathbf{e m u} / \mathbf{g})\end{array}$ & $\mathbf{M}_{\mathbf{r}}(\mathbf{e m u} / \mathbf{g})$ & $\mathbf{H}_{\mathbf{c}}(\mathbf{O e})$ \\
\hline $\mathbf{0}$ & 12.0 & 1.1 & 214 \\
$\mathbf{0 . 5}$ & 9.2 & 0.7 & 197 \\
$\mathbf{1 . 0}$ & 11.4 & 1.1 & 176 \\
$\mathbf{1 . 5}$ & 11.7 & 1.2 & 231 \\
$\mathbf{2 . 0}$ & 12.1 & 1.6 & 134 \\
$\mathbf{2 . 5}$ & 12.3 & 2.2 & 450 \\
$\mathbf{3 . 0}$ & 11.7 & 1.0 & 127 \\
\hline
\end{tabular}

The magnetic properties for all samples were studied by VSM. The magnetic hysteresis loop of $\mathrm{Co}_{0.5} \mathrm{Ni}_{0.5} \mathrm{Fe}_{2} \mathrm{O}_{4}$ before and after encapsulated with PEG-4000 as shown in Fig. 2. The result of VSM analysis are listed in Table 3. The magnetic properties of a magnetic material depend largely on the particle size distributions as the domain structure and magnetization process depends on particle size ${ }^{[5]}$. The coercivity $\left(H_{c}\right)$ of $\mathrm{Co}_{0.5} \mathrm{Ni}_{0.5} \mathrm{Fe}_{2} \mathrm{O}_{4}$ was 214 Oe. The $H_{c}$ decrease after PEG-4000 encapsulation became 127 Oe, respectively. It is due to the decrease of particle size. The result of this study are in the multidomain region. The multidomain particles and the energy anisotropy will be smaller so as to demagnetization require a smaller external field. Thus the value of coercivity decrease. 
The maximum magnetization $\left(M_{\max }\right)$ of $\mathrm{Co}_{0.5} \mathrm{Ni}_{0.5} \mathrm{Fe}_{2} \mathrm{O}_{4}$ was $12.0 \mathrm{emu} / \mathrm{g}$, and decrease after PEG-4000 encapsulation to $11.7 \mathrm{emu} / \mathrm{g}$, its due to PEG-4000 is paramagnetic ${ }^{[15]}$ which weaken the magnetic properties of $\mathrm{Co}_{0.5} \mathrm{Ni}_{0.5} \mathrm{Fe}_{2} \mathrm{O}_{4}$. After the concentration of PEG-4000 increased, then the amount of paramagnetic material increase which lead the value of saturation magnetization decrease by the increasing of PEG-4000 concentration.

\section{SUMMARY}

Nanocrystalline mixed spinel ferrite of $\mathrm{Co}_{0.5} \mathrm{Ni}_{0.5} \mathrm{Fe}_{2} \mathrm{O}_{4}$ nanoparticles has been successfully synthesized by co-precipitation method. The crystallite size before encapsulation was 14.9 $\mathrm{nm}$, after encapsulation PEG-4000 decreased to $7.7 \mathrm{~nm}$ for PEG-4000 of 3gr. Coercivity value before encapsulated was 214 Oe, after encapsulation PEG-4000 decreased to $127 \mathrm{Oe}$ for PEG-4000 of 3 gr. The maximum magnetization before encapsulation was $12.0 \mathrm{emu} / \mathrm{g}$, after encapsulation PEG-4000 decreased to $11.7 \mathrm{emu} / \mathrm{g}$.

\section{ACKNOWLEDGMENTS}

This work was financially supported by Nanofabrication Platform Consortium Project of Nagoya University, Ministry of Culture, Sports, Science and Technology (MEXT), Japan and Grant of "Penelitian Berbasis Kompetensi (PBK)", Ministry of Research, Technology and Higher Education of the Republic Indonesia

\section{REFERENCES}

1 Zia, M., Phull, A.R., \& Ali, J.S. 2016. Synthesis, characterization, applications, and challenges of iron oxide nanoparticles. Nanotechnology, Science and Applications, 9, 49.

2 Kefeni, K.K., Msagati, T.A.M., \& Mamba, B.B. 2017. Ferrite nanoparticles: synthesis, characterisation and applications in electronic device. Mater. Sci. Eng. B, 215, 37.

3 Phadatare, M.R., Salunkhe, A.B., Khot, V.M., Sathish, C.I., Dhawale, D.S., \& Pawar, S.H. 2013. Thermodynamic, structural and magnetic studies of NiFe2O4 nanoparticles prepared by combustion method: Effect of fuel. J. Alloys Compd. 546, 314.

4 Houshiar, M., Zebhi, F., Jafari, Z., Alidoust, A., \& Askari, Z. 2014. Synthesis of cobalt ferrite ( $\mathrm{CoFe} 2 \mathrm{O} 4)$ nanoparticles using combustion, coprecipitation, and precipitation methods: A comparison study of size, structural, and magnetic properties. J. Magn. Magn. Mater. 371, 43.

5 Zhao, L., Yang, H., Cui, Y., Zhao, X., \& Feng, S. 2007. Study of preparation and magnetic properties of silica-coated cobalt ferrite nanocomposites. Journal of materials science, $\mathbf{4 2}, 4110$.

6 Deraz, N.M., \& Abd-elkader, O.H. 2014. Processing and characterization of nanomagnetic $\mathrm{Co}_{0} .5 \mathrm{Ni0} .5 \mathrm{Fe}_{2} \mathrm{O}_{4}$ system. J. Ind. Eng. Chem. 20, 3251.

7 Gul, I.H., Maqsood, A., Naeem, M., \& Ashiq, M.N. 2010. Optical, magnetic and electrical investigation of cobalt ferrite nanoparticles synthesized by co-precipitation route. J. Alloys Compd. 507, 201.

8 Gharagozlou, M. 2009. Synthesis, characterization and influence of calcination temperature on magnetic properties of nanocrystalline spinel Co-ferrite prepared by polymeric precursor method. Journal of Alloys and Compounds, 486, 660.

9 Chen, R., Wang, W., Zhao, X., Zhang, Y., Wu, S., \& Li, F. 2014. Rapid hydrothermal synthesis of magnetic CoxNi1- xFe2O4 nanoparticles and their application on removal of Congo red. Chem. Eng. J. 242, 226. 
10 Maaz, K., Khalid, W., Mumtaz, A., Hasanain, S.K., Liu, J., \& Duan, J.L. 2009. Magnetic characterization of $\mathrm{Co} 1-\mathrm{xNixFe} 2 \mathrm{O} 4(0 \leqslant \mathrm{x} \leqslant 1)$ nanoparticles prepared by co-precipitation route. Physica E: Low-dimensional Systems and Nanostructures, 41, 593.

11 Singhal, S., Singh, J., Barthwal, S.K., \& Chandra, K. 2005. Preparation and characterization of nanosize nickel-substituted cobalt ferrites (Co1- xNixFe2O4). Journal of Solid State Chemistry, 178, 3183.

12 Abdallah, H.M.I., Moyo, T., \& Ngema, N. 2015. The effect of temperature on the structure and magnetic properties of $\mathrm{Co} 0.5 \mathrm{Ni0} .5 \mathrm{Fe} 2 \mathrm{O} 4$ spinel nanoferrite. Journal of Magnetism and Magnetic Materials, 394, 223.

13 Pon-On, W., Charoenphandhu, N., Tang, I.M., Jongwattanapisan, P., Krishnamra, N., \& Hoonsawat, R. 2011. Encapsulation of magnetic CoFe2O4 in $\mathrm{SiO} 2$ nanocomposites using hydroxyapatite as templates: A drug delivery system. Mater. Chem. Phys. 131, 485.

14 Kavas, H., Baykal, A., Toprak, M.S., Köseoğlu, Y., Sertkol, M., \& Aktaş, B. 2009. Cation distribution and magnetic properties of $\mathrm{Zn}$ doped $\mathrm{NiFe} 2 \mathrm{O} 4$ nanoparticles synthesized by PEG-assisted hydrothermal route. Journal of Alloys and Compounds, 479 (1-2), 49.

15 Puspitarum, D.L., Hermawan, A., \& Suharyadi, E. 2016. The influence of PEG-4000 and silica on crystal structure and magnetic properties of magnesium ferrite $\left(\mathrm{MgFe}_{2} \mathrm{O}_{4}\right)$ nanoparticles. AIP Conference Proceedings, 1725 (1), 020065. 